\title{
RANCANG BANGUN RUANG PENGERING UNTUK ALAT PENGERING BIJI KOPI SISTEM KONTINU DENGAN DESIKAN
}

\author{
Harry K. J. Munthe ${ }^{1 *}$, Himsar Ambarita ${ }^{2}$, Dian M. Nasution ${ }^{3}$, Ahmad H. Siregar ${ }^{4}$ \\ ${ }^{1,2,3,4}$ Departemen Teknik Mesin, Fakultas Teknik, Universitas Sumatera Utara \\ Email: harrykevinta12@gmail.com
}

\begin{abstract}
As one of the renewable energy that can be utilized in various fields, solar energy is a potential energy source considering that Indonesia has a tropical climate. One of the uses of solar energy is in agriculture. Various agricultural commodities need to be dried before further processing. Also in coffee commodities that are being favored by many people nowadays. For this reason, as a solution to the problem of long drying times with weather changes issue, a room is made as a drying medium. By sucking hot air from the solar collector using the exhaust, it is expected that heat will be maintained in the space that has been isolated. The dryer rack design is made in layers to make the most of the space. The results of the rooms that have been made are able to keep the lowest temperature at night at $26.6^{\circ} \mathrm{C}$ and the highest temperature at $60.7^{\circ} \mathrm{C}$ during the day. The highest average temperature in the room is on the bottom shelf near the hot air source.
\end{abstract}

Keywords: solar energy, coffee bean dryer, renewable energy

\begin{abstract}
Abstrak
Sebagai salah satu Energi Baru Terbarukan (EBT) yang dapat dimanfaatkan di berbagai bidang, energi surya menjadi sumber energi yang sangat berpotensi mengingat Indonesia yang beriklim tropis. Salah satu pemanfaatan energi surya adalah pada bidang pertanian. Berbagai komoditas hasil pertanian perlu dikeringkan sebelum diproses lebih lanjut. Termasuk juga pada komoditas kopi yang sedang banyak digemari oleh banyak orang. Untuk itu, sebagai solusi dalam permasalahan lama waktu pengeringan dengan cuaca yang berubah-ubah, sebuah ruang dibuat sebagai media pengeringan. Dengan menghisap udara panas dari kolekor surya menggunakan exhaust, diharapkan panas akan terjaga di dalam ruang yang sudah di isolasi. Desain rak pengering dibuat bertingkat agar memanfaatkan ruang dengan maksimal. Hasil daripada ruangan yang sudah dibuat adalah dapat menjaga suhu paling rendah pada malam hari sebesar $26,6{ }^{\circ} \mathrm{C}$ dan suhu tertinggi sebesar $60,7^{\circ} \mathrm{C}$ pada siang hari. Untuk suhu tertinggi rata-rata pada ruangan berada di rak paling bawah dekat sumber udara panas.
\end{abstract}

Kata kunci : energi surya, alat pengering biji kopi, energi terbarukan

\section{PENDAHULUAN}

Sebagai salah satu negara penghasil kopi terbesar dunia di urutan ke-4, Indonesia harus bisa memanfaatkan peluang besar yang ada untuk bisa meningkatkan kualitas dan juga kuantitas produksi kopi [1]. Pengeringan adalah proses penghilangan massa air dari suatu benda dengan penguapan kandungan air yang ada pada benda tersebut. Namun pengeringan cara konvensional ini memiliki permasalahan pada saat saat cuaca mendung atau hujan ssehingga dibutuhkan suatu alat sebagai media pengering dan juga penjaga keadaan udara. 


\section{TEORI DASAR}

\subsection{Energi Surya}

Energi surya adalah salat satu sumber energi terbarukan dan berkelanjutan karena keberadaanya yang tidak akan habis. Energi surya sampai ke bumi dalam bentuk energi panas dengan prinsip perpindahan panas radiasi. Sebagai energi terbarukan, energi surya semakin lama semakin dikembangkan agar bisa dimanfaatkan lebih lagi.

Matahari mempunyai diameter $1,39 \times 109 \mathrm{~m}$. Bumi mengelilingi matahari dengan lintasan berbentuk ellipse dan matahari berada pada salah satu pusatnya. Jarak rata-rata matahari dari permukaan bumi adalah 1,49×1011 m [2, 3]. Lintasan bumi terhadap matahari berbentuk ellipse, maka jarak antara bumi dan matahari adalah tidak konstan. Karena adanya perbedaan jarak ini, menyebabkan radiasi yang diterima atmosfer bumi juga akan berbeda

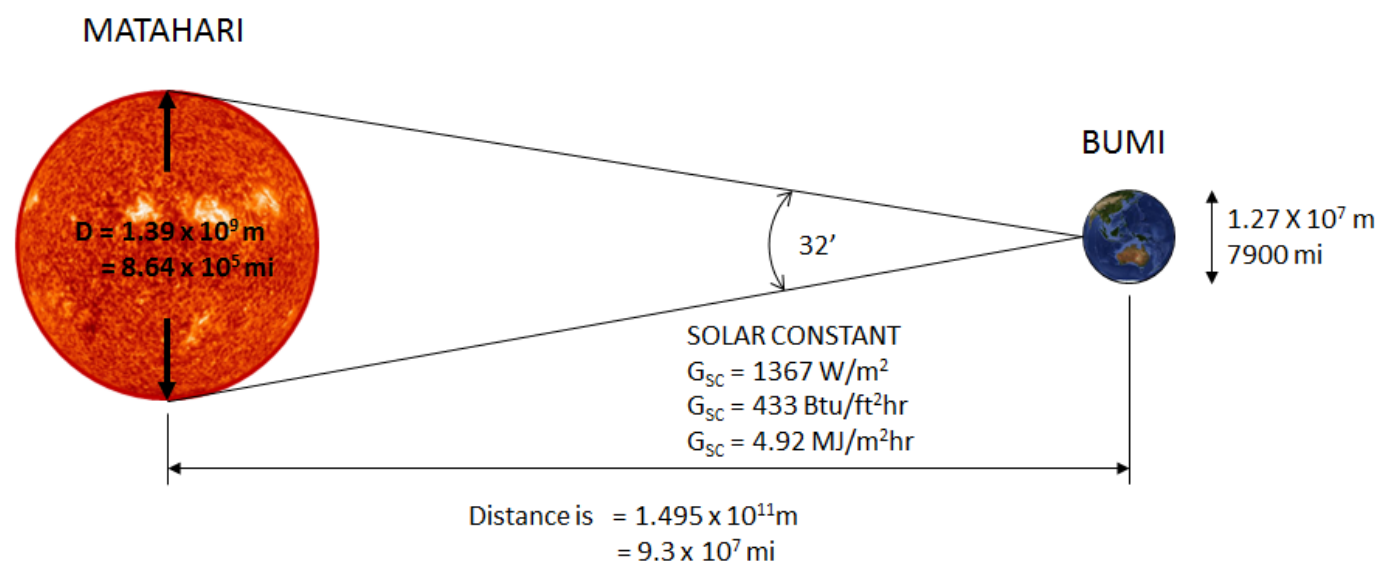

Gambar 2.1 Hubungan Matahari dan Bumi

\subsection{Pengeringan Tenaga Surya (Solar Dryer)}

Pengeringan adalah proses pengurangan kadar air yang relatif kecil secara terusmenerus pada suatu bahan [4]. Metode pengeringan dengan energi matahari secara umum terbagi atas dua, yaitu pengeringan sinar matahari (direct sun drying), dimana produk yang akan dikeringkan langsung dijemur di bawah sinar matahari. Dan metode pengeringan surya (solar drying), dimana produk yang akan dikeringkan diletakkan di dalam suatu alat pengering.

Pengering tenaga surya (solar dryer) adalah cara pengeringan dengan memanfaatkan energi matahari menggunakan kolektor sebagai penyerap panas yang menjadikan penggunaan energi matahari yang lebih maksimal.

\subsection{Kolektor Surya}

Pengering surya adalah suatu sistem pengering yang memanfaatkan energi surya. Sistem pengering surya terdiri dari dua bagian utama yaitu kolektor surya dan ruang 
pengering. Kolektor surya adalah suatu alat yang dapat mengumpulkan atau menyerap radiasi surya dan mengkonversikan menjadi panas.

Kolektor surya dapat didefinisikan sebagai sistem perpindahan panas yang menghasilkan energi panas dengan memanfaatkan radiasi sinar matahari sebagai sumber energi utama. Kolektor surya yang pada umumnya memiliki komponen-komponen utama, yaitu [5]:

1. Cover berfungsi untuk mengurangi rugi panas secara konveksi menuju lingkungan.

2. Absorber berfungsi untuk menyerap panas dari radiasi cahaya matahari.

3. Kanal berfungsi sebagai saluran transmisi fluida kerja.

4. Isolator berfungsi meminimalisasi kehilangan panas secara konduksi dari absorber menuju lingkungan.

5. Frame berfungsi sebagai struktur pembentuk dan penahan beban kolektor.

\subsection{Teori Perpindahan Panas}

Panas adalah salah satu bentuk energi yang dapat dipindahkan dari suatu tempat ke tempat lain, tetapi tidak dapat diciptakan atau dimusnahkan sama sekali. Dalam suatu proses, panas dapat mengakibatkan terjadinya kenaikan suhu suatu zat dan atau perubahan tekanan, reaksi kimia dan kelistrikan. Perpindahan kalor/panas (heat transfer) ialah ilmu untuk meramalkan perpindahan energi yang terjadi karena adanya perbedaan suhu di antara benda atau material. Dimana perpindahan panas ini merupakan satu dari disiplin ilmu teknik termal yang mempelajari cara menghasilkan panas, menggunakan panas, mengubah panas, dan menukarkan panas di antara sistem fisik. Proses terjadinya perpindahan panas dapat dilakukan secara langsung, yaitu fluida yang panas akan bercampur secara langsung dengan fluida dingin tanpa adanya pemisah dan secara tidak langsung, yaitu bila diantara fluida panas dan fluida dingin tidak berhubungan langsung tetapi dipisahkan oleh sekat-sekat pemisah. Peneliti [6] mengklasifikasikan perpindahan panas dalam tiga bahagian yaitu : konduksi, konveksi, radiasi. Dimana ketiga hal tersebut dapat di ilustrasi dari proses sederhana berikut.

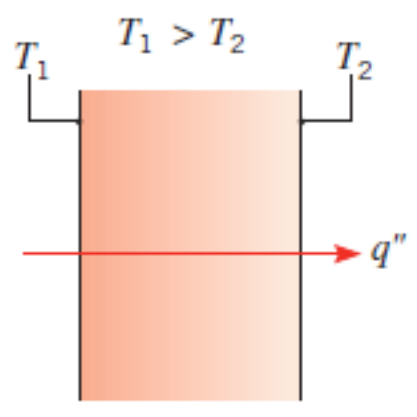

Gambar 2.3 Perpindahan panas secara konduksi

Dari gambar 2., dengan memperhatikan material batang, sebagai contoh plastik, akan ditemukan bahwa kesebandingan diatas adalah valid. Namun, kita juga menemukan bahwa untuk nilai $A, \Delta x$, dan $\Delta T$ yang sama, akan menghasilkan nilai $q_{x}$ yang lebih kecil untuk material plastik dibandingkan bermaterial logam. Sehingga kesebandingan diatas 
dapat ditulis dalam bentuk persamaan dengan memasukkan koefisien yang dipengaruhi oleh material. Berdasarkan pada hukum Fourier, persamaan 2.2, konduktifitas termal didefenisikan sebagai :

$$
k=\frac{q_{k} / A}{|d T / d x|}
$$

$k$ adalah konduktivitas thermal (W/m.K), yang merupakan sifat material yang penting karena sangat mempengaruhi nilai perpindahan panas yang terjadi pada sebuah benda. Berikut merupakan nilai konduktivitas panas untuk beberapa material :

\subsubsection{Perpindahan Panas Konveksi}

Konduksi dan konveksi adalah membutuhkan media perantara dalam proses perpindahan panasnya. Namun pada konveksi membutuhkan gerakan fluida untuk dapat memindahkan panas. Penelitian menunjukkan bahwa perpindahan panas konveksi sangat bergantung pada sifat-sifat fluida seperti viskositas dinamis $\mu$, konduktivitas termal $k$, massa jenis $\rho$, dan spesifik panas $C_{p}$, dan dipengaruhi oleh kecepatan fluida $V$. Konveksi juga bergantung pada bentuk dan kekasaran permukaan, dan bahkan juga dipengaruhi oleh tipe aliran seperti laminar atau turbulen. Sehingga dapat disimpulkan bahwa perpindahan panas secara konveksi adalah kompleks karena bergantung pada banyak variabel. Oleh karena itu, konveksi adalah mekanisme perpindahan panas yang paling kompleks. Meskipun konveksi adalah kompleks, setelah diamati bahwa laju perpindahan panas secara konveksi berbanding lurus dengan perbedaan temperatur dan dapat ditulis dengan Hukum Newton tentang pendinginan. Berikut adalah skematik perpindahan panas secara konveksi :

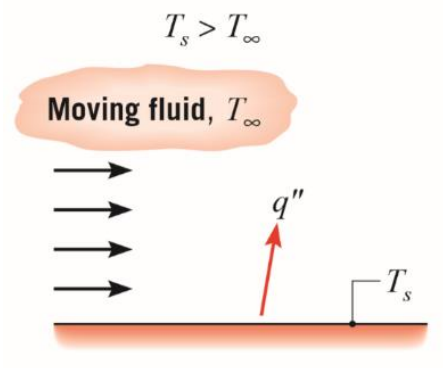

Gambar 2.4 Perpindahan panas secara konveksi

Untuk nilai perpindahan panas secara konveksi dapat di tentukan dengan rumus:

$$
q_{\text {konveksi }}=h A_{s}\left(T_{s}-T_{\infty}\right)
$$

dengan $\quad h$ : koefisien perpindahan panas konveksi $\left(\mathrm{W} / \mathrm{m}^{2} \mathrm{~K}\right)$

$A_{s}$ : luas permukaan perpindahan panas $\left(\mathrm{m}^{2}\right)$

$T_{s}$ : temperatur permukaan benda $(\mathrm{K})$

$T_{\infty}$ : merupakan temperatur lingkungan sekitar benda

\subsubsection{Perpindahan Panas Radiasi}

Radiasi berbeda dengan mekanisme perpindahan panas secara konduksi dan secara konveksi. Perpindahan panas secara radiasi tidak membutuhkan kehadiran suatu 
material sebagai media perantara perpindahan panas. Faktanya, energi yang ditransfer dengan radiasi adalah yang tercepat (secepat kecepatan cahaya) dan dapat terjadi pada ruangan vakum. Perpindahan panas secara konduksi dan konveksi terjadi dari temperatur yang tinggi ke temperatur yang lebih rendah. Pada radiasi, perpindahan panas dapat terjadi pada 2 benda yang memiliki temperatur yang tinggi dan dipisahkan oleh benda yang memiliki temperatur yang lebih rendah. Berikut merupakan skematik proses terjadinya perpindahan panas secara radiasi :

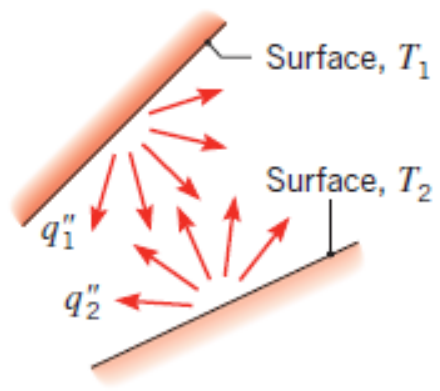

Gambar 2.5 Proses perpindahan panas radiasi

Joseph Stefan dan Boltzmann menetapkan sebuah hukum yang ditetapkan secara eksperimental untuk menentukan besarnya energi radiasi yang dipancarkan oleh sebuah blackbody yang disebut dengan hukum Stefan-Boltzmann.

$$
Q_{\text {radiasi }}=\sigma A T^{4}
$$

Dimana $\sigma=5,669 \times 10^{-8} \mathrm{~W} / \mathrm{m}^{2} \mathrm{~K}^{4}$ adalah konstanta proporsionalitas dan disebut konstanta Stefan-Boltzmann dan $T$ adalah temperatur absolut dari suatu permukaan (K).

\subsection{Biji Kopi}

Biji kopi merupakan bahan dasar untuk penyeduhan kopi. Dari sekian banyak jenis biji kopi, terdapat 2 jenis biji kopi yang dijual di pasar pada umumnya, yaitu biji kopi robusta dan biji kopi arabika. Masing-masing jenis biji kopi ini memiliki keunikan dan pasarnya sendiri. Pada penelitian kali ini digunakan biji kopi arabika karena ketersediaan biji di daerah tempat penelitian.

Biji kopi arabika sering disebut biji kopi dengan cita rasa terbaik. Tingkat kafein dari biji kopi jenis ini sebesar 0,8\%-1,4\%. Budidaya tanamannya biasa dilakukan di ketinggian 700-1700 mdpl. Sehingga suhu tumbuh optimalnya sekitar $16-20{ }^{\circ} \mathrm{C}$. Kopi arabika adalah kopi yang paling baik, tanda-tandanya adalah biji picak dan daun yang hijau tua dan berombak-ombak. Agar baik tumbuhnya maka hendaknya tinggi kadar bahan organis dalam tanah yang ditanami dengan kopi Arabika itu, ditanam berbagai macam leguminosae sebagai pupuk hijau didekat kopi tersebut serta pohon-pohon pelindung

Pengolahan buah kopi bertujuan untuk memisahkan biji kopi dari kulitnya dan mengeringkan biji tersebut sehingga diperoleh kopi beras dengan kadar air tertentu dan siap dipasarkan. Kadar air kopi optimum adalah 11-12\%, bila lebih dari 13\% akan mudah terserang cendawan sedangkan bila kurang dari $10 \%$ akan mudah pecah. Pengolahan 
buah kopi dilakukan melalui dua cara, yaitu cara basah karena prosesnya banyak menggunakan air dan cara kering karena tidak menggunakan air dalam prosesnya.

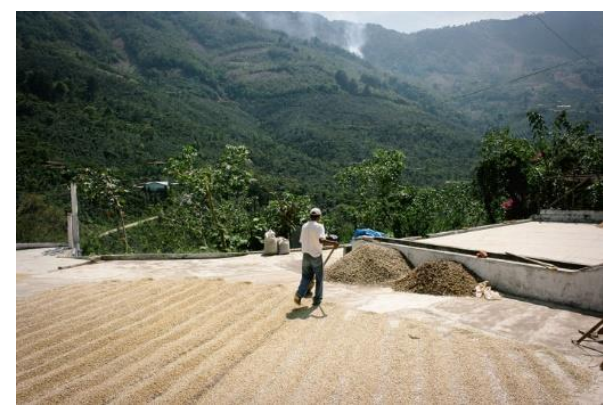

Gambar 2.8 Pengeringan Biji Kopi Konvensional

\subsection{Proses Pengeringan Biji Kopi}

Struktur buah kopi (coffee cherry) terdiri dari pericarp (kulit daging terluar) dan biji kopi. Pericarp sendiri terdiri lagi dari beberapa lapisan seperti kulit, daging kulit, layer getah (yang biasanya terdiri dari gula alami dan semacam kandungan alkohol) dan perkamen. Lapisan pericarp adalah yang paling sering dibersihkan, namun lapisan ini juga berpengaruh dalam menambah rasa pada kopi.

Proses pengeringan basah bertujuan untuk menghilangkan semua kulit-kulit daging yang melekat pada biji kopi sebelum dikeringkan. Setelah dipanen, ceri-ceri kopi biasanya 'diseleksi' terlebih dahulu dengan merendamnya di dalam air. Ceri yang mengapung akan dibuang, sementara yang tenggelam akan tetap dibiarkan untuk proses lanjutan karena ceri-ceri demikian dianggap telah matang.

Selanjutnya kulit luar dan kulit daging ceri kopi akan dibuang dengan menggunakan mesin khusus yang disebut depulper (pengupas). Biji kopi yang sudah terlepas dari kulitnya ini kemudian dibersihkan lagi dengan memasukkannya ke dalam bejana khusus berisi air agar sisa-sisa kulit yang masih melekat bisa luruh sepenuhnya akibat proses fermentasi.

Durasi, atau lamanya kopi difermentasi ini berbeda-beda pada setiap produsen. Namun umumnya berkisar antara 24-36 jam tergantung temperatur, ketebalan layer getah pada ceri kopi, dan konsentrat enzimnya. Jika suhu di sekitarnya semakin hangat, maka prosesnya akan semakin cepat pula

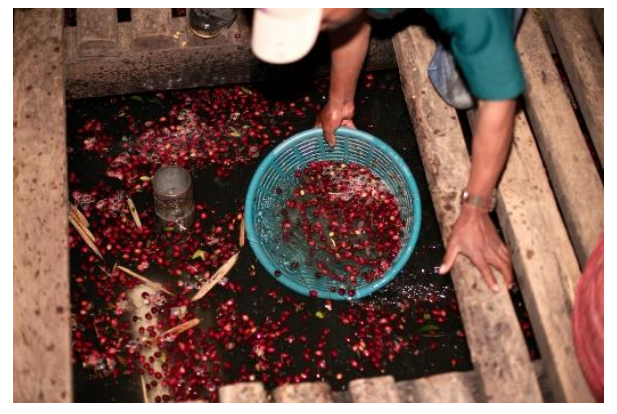




\section{Gambar 2.10 Proses Pengeringan Basah}

\section{HASIL DAN PEMBAHASAN}

\subsection{Desain Alat}

Pengeringan pada prinsipnya merupakan cara menghilangkan kandungan air dari suatu benda dengan diberi kalor. Prinsip kerja pengeringan pada alat pengering ini secara umum sangat sederhana. Biji kopi di simpan dalam suatu ruangan yang dijaga suhunya, kemudian diberikan aliran udara panas secara kontinu. Berikut dibawah ini desain dari rancang bangun alat dengan menggunakan software SolidWorks 2015.

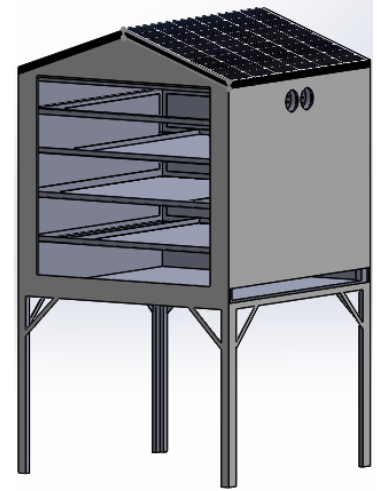

Gambar 4.1 Desain Ruang Pengering

- Desain rangka

Rangka ruang pengering dibuat dari besi pelat $\mathrm{L} 30 \mathrm{~mm} \times 30 \mathrm{~mm}$ dengan tebal 3 mm yang di sambungkan dengan menggunakan las listrik.

Ukuran tinggi : $2000 \mathrm{~mm}$

Ukuran lebar : $1135 \mathrm{~mm}$ x $1135 \mathrm{~mm}$

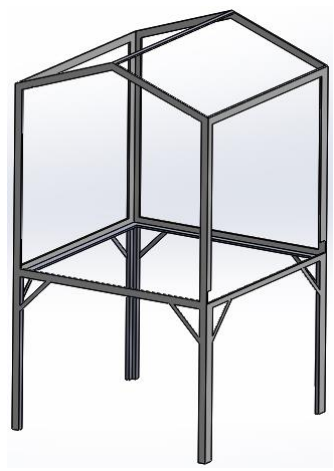

Gambar 4.2 Desain Rangka Ruang Pengering

- Desain rak (tray)

Rak dibuat dari alumunium pelat L $30 \mathrm{~mm}$ x $30 \mathrm{~mm}$ dengan ketebalan $2 \mathrm{~mm}$.

Penyambungan antar pelat dan penyambungan jarring-jaring menggunakan paku rivet.

Ukuran rangka $\quad: 1000 \mathrm{~mm} \times 1000 \mathrm{~mm}$

Ukuran jarring-jaring $\quad: 1000 \mathrm{~mm} \times 800 \mathrm{~mm}$ 


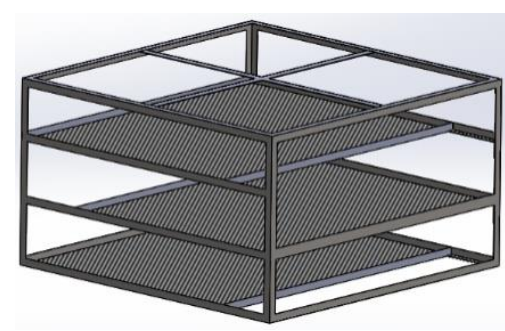

Gambar 4.5 Desain Rak (Tray)

\subsection{Rancang Bangun Alat}

Proses langkah-langkah pengerjaan alat yang sudah di desain :

- Pembuatan rangka.

- Pemasangan dinding pelat seng.

- Pemasangan isolator dinding.

- Pembuatan rak (tray).

- Pemasangan exhaust.

\subsection{Hasil Pengujian Pengeringan}

Dari hasil percobaan selama 3 hari, didapat data berupa perubahan massa dari biji kopi, temperatur dan kelembapan ruang pengering. Untuk temperatur paling tinggi didapat sebesar $60,7^{\circ} \mathrm{C}$ pada hari pertama pukul 14.15. Untuk pengeringan biji kopi agar tetap baik kualitasnya maksimal $60^{\circ} \mathrm{C}$.

Pada penempatan sensor temperatur dan kelembapan diletakkan pada setiap lapis (layer) rak. Karena pembuatan ruang pengering sejumlah 2, maka terdapat 6 sensor yang digunakan.

Ruang 1

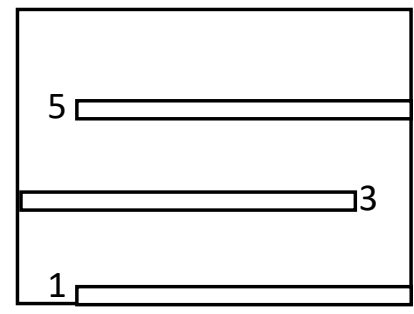

Ruang 2

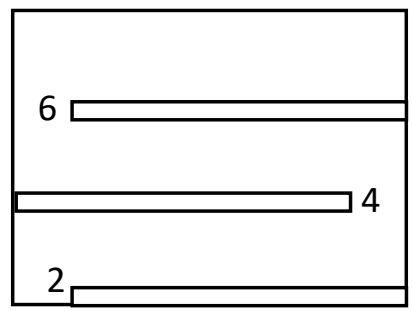

Gambar 4.13 Letak Penempatan Sensor Temperatur dan Kelembapan

Berikut adalah hasil dari pada pengukuran temperatur dan kelembapan pada pengujian hari pertama yaitu tanggal 23 April 2019 pukul 8.00 sampai 24 April 2019 pukul 8.00. 


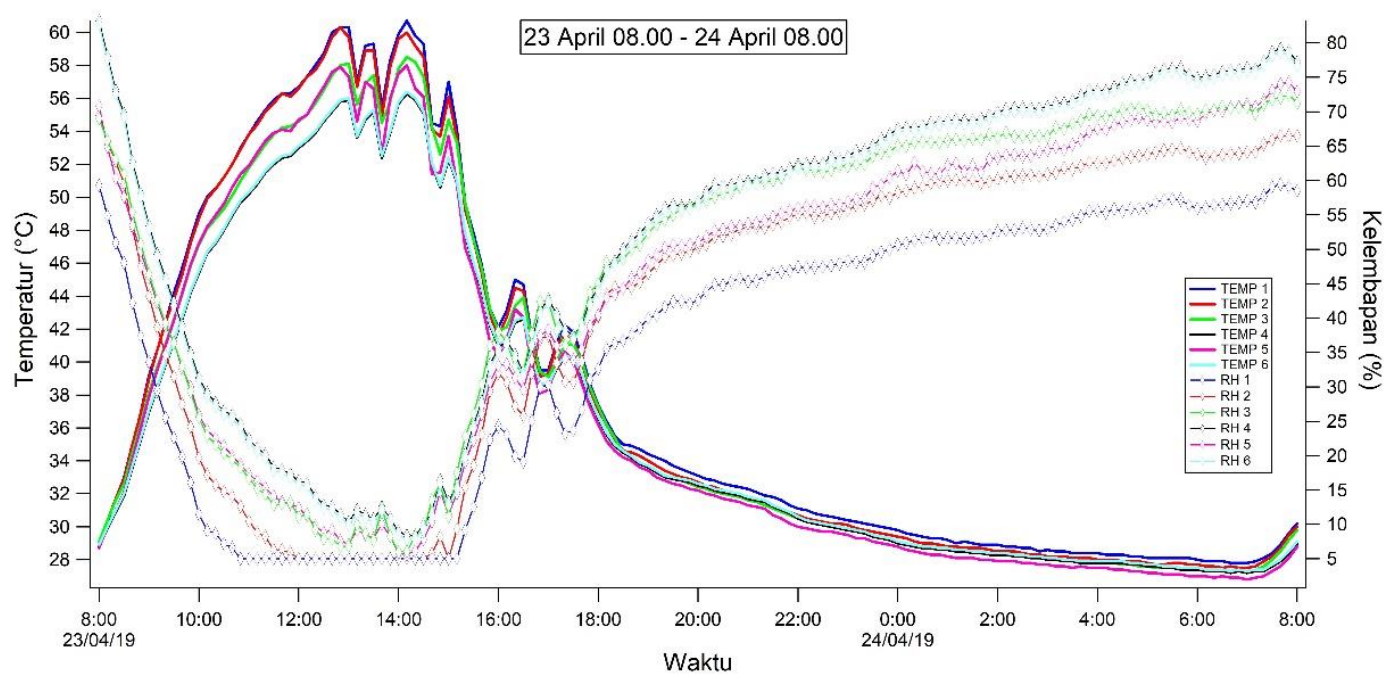

Grafik 4.1 Temperatur dan Kelembapan Pengujian Hari Pertama

Berikut adalah hasil dari pada pengukuran temperatur dan kelembapan pada pengujian hari kedua yaitu tanggal 24 April 2019 pukul 8.00 sampai 25 April 2019 pukul 8.00 .

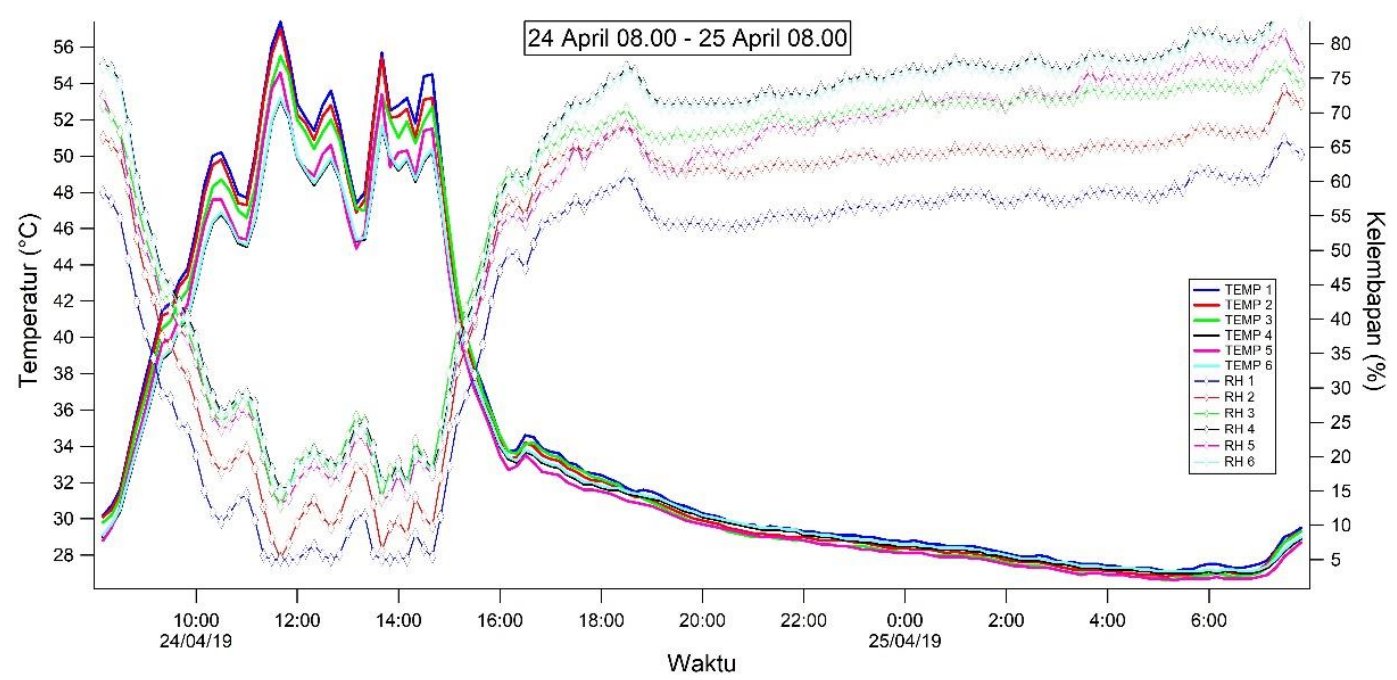

Grafik 4.2 Temperatur dan Kelembapan Pengujian Hari Kedua

Berikut adalah hasil dari pada pengukuran temperatur dan kelembapan pada pengujian hari ketiga yaitu tanggal 25 April 2019 pukul 8.00 sampai pukul 18.00. 


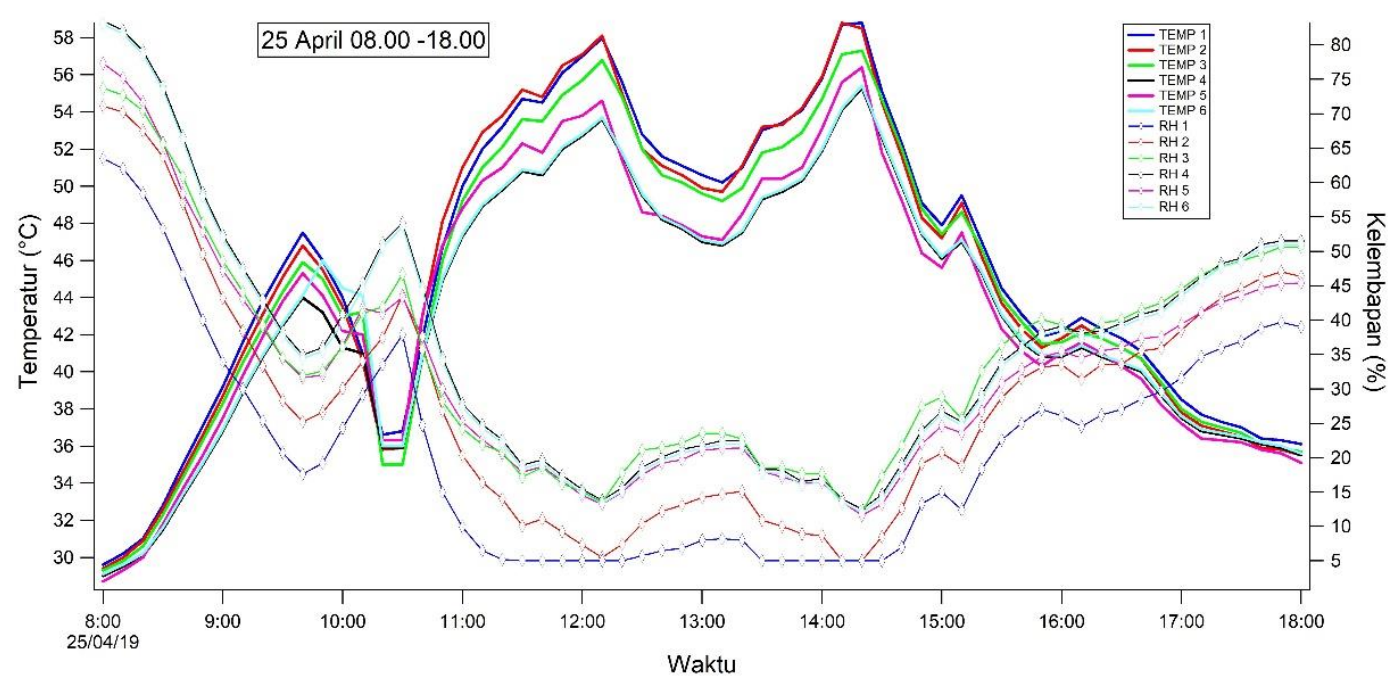

Grafik 4.3 Temperatur dan Kelembapan Pengujian Hari Ketiga

\section{KESIMPULAN DAN SARAN}

\subsection{Kesimpulan}

Adapun kesimpulan yang didapat dari pengujian ini adalah :

1. Telah dirancang dan dibuat sebuah ruang pengering untuk mengeringkan biji kopi dengan ukuran ruangan $1135 \mathrm{~mm}$ x $1135 \mathrm{~mm}$ x $1135 \mathrm{~mm}$. Tinggi keseluruhan alat $2000 \mathrm{~mm}$. Dalam ruang pengering terdapat 3 tingkat rak tempat biji kopi diletakkan dengan masing-masing ukuran rak selebar $800 \mathrm{~mm}$ x 1000 $\mathrm{mm}$.

2. Dari data yang didapat, temperatur dan kelembapan tiap rak berbanding terbalik. Untuk margin perbandingan yang paling jauh terletak di rak paling bawah tiaptiap ruang. Ini dikarenakan rak paling bawah terletak paling dekat dengan lubang sumber udara panas masuk.

3. Pencatatan massa pada ruang 1 dan ruang 2 sangat dipengaruhi oleh intensitas matahari. Dimana terlihat pada siang hari saat cerah, massa biji kopi mengalami penurunan. Namun pada malam hari, perubahan massa tetap terjadi di kedua ruang akibat kelembapan udara tinggi, baik yang menggunakan desikan dengan yang tidak menggunakan desikan.

\subsection{Saran}

Adapun saran untuk perbaikan pengujian ini adalah :

1. Diperlukan pengujian lebih lanjut terhadap penggunaan desikan, bagaimana wujud yang optimal untuk menjaga tingkat kelembapan.

2. Penggunaan jenis sensor massa yang lebih bagus agar pencatatan data lebih akurat dan tidak terjadi fluktuatif yang rancu.

3. Pembuatan isolasi ruang pengering yang lebih baik. Terutama pada pembuatan isolasi untuk menutup pada malam hari agar udara malam yang lembap tidak masuk ke ruang pengering. 


\section{REFERENSI}

1. Ambarita, Himsar. 2011a. Energi Surya. Medan: Departemen Teknik Mesin FT USU.

2. Ambarita, Himsar. 2011b. Perpindahan Panas Konveksi dan Pangantar Alat Penukar Kalor. Medan: Departemen Teknik Mesin FT USU.

3. Yunus, A. Cengel. 2002. Heat Transfer A Practical Approach. Second Edition. MC Graw Hill, Book Company, Inc: Singapore.

4. Incropera, F. P., and Dewitt. D. P.. 1196. Fundamentals of Heat and Mass Transfer. Fourth Edition. John Wiley \& Sons. New York.

5. Panggabean, E., 2011. Buku Pintar Kopi. PT Agromediam Pustaka, Jakarta 